\title{
Journal of Career Development
}

http://jcd.sagepub.com

\section{Career Barriers Among Native American Students Living on Reservations \\ Laura L. Hoffmann, Aaron P. Jackson and Steven A. Smith \\ Journal of Career Development 2005; 32; 31 \\ DOI: $10.1177 / 0894845305277038$ \\ The online version of this article can be found at: http://jcd.sagepub.com/cgi/content/abstract/32/1/31}

\author{
Published by: \\ (5)SAGE Publications \\ http://www.sagepublications.com \\ On behalf of: \\ $\sqrt{7}$ \\ 25 \\ University of Missouri-Columbia
}

Additional services and information for Journal of Career Development can be found at:

Email Alerts: http://jcd.sagepub.com/cgi/alerts

Subscriptions: http://jcd.sagepub.com/subscriptions

Reprints: http://www.sagepub.com/journalsReprints.nav

Permissions: http://www.sagepub.com/journalsPermissions.nav

Citations (this article cites 16 articles hosted on the SAGE Journals Online and HighWire Press platforms):

http://jcd.sagepub.com/cgi/content/refs/32/1/31 


\title{
Career Barriers Among Native American Students Living on Reservations
}

\author{
Laura L. Hoffmann \\ Aaron P. Jackson \\ Steven A. Smith \\ Brigham Young University
}

\begin{abstract}
Patterns of educational achievement and employment indicate that Native American students face considerable barriers to career development. This is particularly true for those who live on reservations. This study used a hermeneutic analysis of qualitative interview data to identify and describe these barriers from the perspective of 29 Native American students in reservation secondary schools. Themes related to the barriers faced by these students are described and discussed.
\end{abstract}

Keywords: career barriers; Native American; secondary; reservation

Datterns of educational achievement and employment among Native Ameri1 cans indicate that this population faces considerable barriers to education and career development. Unemployment rates are higher for Native Americans, and the standard of living is lower than for the rest of the population (A. P. Jackson \& Turner, 2004). The average income for Native Americans is $\$ 21,750$, in contrast to the general population average income of $\$ 35,225$ (A. P. Jackson \& Turner, 2004). Poverty rates among Native Americans are at $31 \%$ and are considerably higher than the general population rates, which are at $13 \%$ (A. P. Jackson \& Turner, 2004). Education achievement lev-

Authors' Note: An earlier version of this study was presented at the Annual Meeting of the National Career Development Association in Denver, Colorado, June 2003. Aaron P. Jackson, 340-J MCKB, Brigham Young University, Provo, UT 84602; (801) 422-8031; fax: (801) $422-$ 0198; email: aaron_jackson@byu.edu. 
els of Native Americans are lower than the general population's education achievement levels. Only 9.3\% of Native Americans hold a bachelor's degree or higher, as opposed to $20.3 \%$ of the general population (A. P. Jackson \& Turner, 2004). This discrepancy is even more pronounced for individuals living on reservations. Among these individuals, only $41 \%$ older than the age of 25 are high school graduates, and only 5\% are college graduates (U.S. Bureau of the Census, 1990; U.S. Department of Commerce, 1993). A staggering 58\% of Native Americans residing on reservations are living below the poverty level (U.S. Department of Commerce, 1993). Despite these statistics, studies have also shown that if Native American students persist in college and graduate, they fare as well as or better than the general population in their postgraduate income and the rate they complete graduate programs (U.S. Department of Education, 1998).

The discrepancy between Native Americans' academic achievement and abilities is disturbing. For instance, despite an increase in enrollment into higher education, it appears that Native Americans do not persist in education at the same rate as the general population or even at the same rate as other minority groups. Data show that the persistence to graduation within 6 years is $36 \%$, which is lower than the general population graduation rate of $56 \%$. And Native American graduation rates are lower than other minority populations (Reddy, 1993; U.S. Department of Education, 1998). Native American students who do graduate from college report experiencing considerable difficulties in their postsecondary experience (A. P. Jackson, Smith, \& Hill, 2003).

Recent research has focused on understanding the perceived barriers faced by college-age students. Swanson and Tokar (1991) completed a study of college students' perceived barriers to careers. They found that finances and study skills were most often cited by this population as barriers to achieving their desired careers. Also cited as barriers were job discrimination and family and work obligations (Swanson \& Tokar, 1991). In another study focusing on ethnic differences in perceived barriers, Luzzo (1993) found significant differences of perceptions between ethnic groups in the barriers of ethnic identity, study skills, and finances. Luzzo and McWhirther (2001) conducted a study of educational and career-related barriers and found that ethnic minorities in general anticipate more career-related barriers than their European American counterparts.

Although these studies have begun to identify the career barriers diverse ethnic populations may face, only one of the studies cited above included Native Americans in their sample. And in that study, Native Americans 
accounted for only $2 \%$ of the sample. Another deficit in the research on barriers has been the focus on college-age students rather than K-12 students. McWhirther (1997) argued that the barriers experienced or perceived before college may be more important than those experienced by college students because the secondary years are when important decisions are being made concerning college and career. She looked at the perceived barriers of Mexican American high school students and found that they perceived more barriers than European American students. No comparable research has been conducted with Native American students. McWhirther specifically suggested that research be conducted on career barriers experienced by Native American high school students.

A number of scholars have suggested possible barriers to academic and career achievement for Native American students. These identified barriers include lack of information about careers (Hoover \& Jacobs, 1992), cultural factors (Benjamin, Chambers, \& Reiterman, 1993), and feelings of isolation (Lin, LaCounte, \& Eder, 1988). In addition, A. P. Jackson and Smith (2001) cited family pressures, economic depression, and perceived hostility as factors influencing postsecondary transitions among Native Americans.

As with the general population, most studies of Native Americans' perceived barriers have focused on college-age students instead of high school students. These studies have also used primarily quantitative methods. That is, they have used existing surveys, models, and instruments that may limit the findings to a particular paradigm that may or may not fit this particular population. A. P. Jackson and Smith (2001) suggested the use of qualitative methods to better understand the experience of these students. McWhirther (1997) and Brown and Kurpius (1997) also concluded that qualitative research is needed to capture the experience of Native American students.

Although qualitative methods have been used to study Native American students in the midst of postsecondary transition (A. P. Jackson \& Smith, 2001) as well as those who have successfully graduated from college (A. P. Jackson, Smith et al., 2003), little research has been done on the perceptions of career barriers from the perspective of American Indian secondary school students. It is important to understand the barriers these students face to better understand how to help them make effective educational and vocational transitions. This study used qualitative interviews to explore the range of careers that Native American secondary students are considering as well as the barriers they see standing in their way of being successful in those careers. Their anticipated means of overcoming barriers were also explored. 


\section{Method}

\section{Participants}

All participants were Native American students attending one of four secondary schools on the Navajo Nation. Informed consent was obtained from the students and their parents prior to their participation. Twenty-nine students were interviewed. The participants included 14 female and 15 male students. One was a 7th grader, 5 were 8 th graders, 5 were 9th graders, 7 were 10th graders, 6 were 11 th graders, and 6 were 12th graders. The diversity of gender and grade levels among the participants was consistent with the exploratory nature of the study and the study's focus on secondary students' experiences.

The interviews were conducted by professors and graduate students as part of services provided through a GEAR UP grant. All of the investigators and one additional doctoral student were involved in conducting the interviews. The investigators included two male European American faculty members and two female European American doctoral students. All interviewers had received both academic and practical training in qualitative methods.

\section{Procedure}

Interviews took place at the student's schools as part of scheduled semiannual academic and career planning meetings. Participants were selected randomly from among students attending these meetings. The interviews were conducted at the end of the planning meetings. Although parents participated in the planning meetings, all of the follow-up interviews used for this research were done one on one. A basic list of interview questions was constructed to guide the interview process (see the appendix). The interviews ranged from 15 to $30 \mathrm{~min}$ in length. The participants were asked what they saw themselves doing educationally and vocationally after high school. They were then asked what they thought might keep them from achieving those aspirations. The interview also included questions asking what they felt they could do to overcome any perceived barriers and who they could get support from in trying to do so.

Although the interviews were guided by several basic questions (see the appendix), the interviews were unstructured. The interviewers used follow-up questions, minimal encouragers, and other basic interviewing skills to gain more information and deepen participant responses. This interviewing method followed a relational ontology as a philosophical foundation. This approach assumes that it is within the context of a relationship that human experiences are best understood (A. P. Jackson, Slife, \& Williams, 2003; Schwandt, 2000). 
Kvale (1996) described the qualitative interview as a way to "obtain descriptions of the lived world of the interviewees with respect to interpretations of the meaning of the described phenomena" (p. 30). Accordingly, the researchers attended to the following principles in the interviews:

1. Attention to the everyday "life world" of the participants.

2. Efforts to understand the meaning of the themes in the dialogue.

3. Dialogue aimed at qualitative rather than quantitative knowledge.

4. Encouragement of in-depth descriptions of the participants' experience.

5. Encouragement of descriptions of specific experiences.

6. A deliberate openness to novel and unexpected perspectives.

7. Focus on the phenomena of interest without using restrictive questions.

8. Acknowledgement of possible ambiguities and contradictions in the dialogue.

9. Awareness of new insights that may come in the interview.

10. Knowledge that each interviewer brings varying degrees of sensitivity to different aspects of the participants' experiences and perspectives (Kvale, 1996, pp. 30-31).

\section{Analysis}

The interviews were recorded and transcribed. The transcripts were then interpreted by the researchers using a hermeneutic qualitative method (Kvale, 1987, 1996; Packer, 1985). The interpretation of the transcribed interviews followed the same philosophical tenets as the interviews themselves. The analysis was conducted as follows:

1. An unfocused reading of the text. This is an attempt to empathically gain an understanding of meaning articulated in the interviews by the participants. This is done with as few assumptions as possible to accurately understand the meanings conveyed (A. P. Jackson \& Patton, 1992; Kvale, 1996).

2. Interpretations through successive readings of the material. This is referred to by Kvale (1996) as a spiral - the idea being that deeper meanings are uncovered with successive readings (Hoshmand, 1989; Kvale, 1996; Polkinghorne, 1984, 1991).

3. Explanation of the findings using language that accurately conveys the meaning in the text. The goal is to clearly and precisely describe the themes (Kvale, 1987, 1996).

Two of the researchers conducted the analysis of the transcribed interviews. Each of the researchers analyzed the transcripts independently using the above method to develop a set of initial themes. This process entailed an initial reading of the transcripts followed by several successive readings in which themes 
were identified and modified. Once each researcher had independently established a set of initial themes, they came together to continue the analysis. This consisted of retaining the themes found by both researchers and determining whether the remaining possible themes were valid. This was accomplished by both researchers reanalyzing the remaining themes using the above method. Only those themes found valid by both researchers were retained.

\section{Results}

In this study, we identified both surface themes and complex themes. The surface themes were readily apparent in the interviews and in the initial phase of the analysis. They were typically identified in dialogue about careers of interest, obvious barriers faced in entering a career, and methods students planned to use to overcome these barriers. The complex themes typically became apparent later in the interviews and were identified only after considerable analysis. The strength of the qualitative method used in this study was in being able to gain information and understanding beyond the surface themes. The unstructured nature of the interviews allowed students and researchers to clarify and better understand both the surface information discussed as well as the deeper, more complex content of the interviews. We will first describe the surface themes and then discuss the complex themes.

\section{Surface Themes}

\section{Limited Range of Possible Careers}

The male students typically identified such potential careers as mechanic, ironworker, welder, engineer, and carpenter. Electrician, veterinarian, musician, computer technician, and military careers were also mentioned. Female students' career goals were more varied and included doctor, nurse, teacher, lawyer, cook, artist, architect, photographer, animal care worker, and veterinarian. The vast majority of careers identified by the students were concrete, sex-typical careers (cf. Gottfredson, 1981).

\section{Perceived Barriers}

School. Potential barriers caused by academic difficulties in math, science, and English were specifically noted by students, as illustrated in the following sample of dialogue: 
Interviewer: What kind of things do you feel like get in your way of doing that? Participant: Probably school.

Interviewer: What do you mean?

Participant: Like, all the hard work and stuff like that.

Money. Students discussed money as an obstacle to achieving their goals. As one student stated,

Participant: I want to attend Harvard or Stanford, that's what I really want to do. But thinking realistically, I don't think my family could afford it.

Those students who had an identified career option and perceived themselves as having support from others or who had siblings who were in college were less likely to see college itself as an obstacle and were more likely to see finances as their chief obstacle.

Family and peer pressure. Students reported feeling some pressure from family and friends to not leave the reservation. The following interview illustrated this:

Interviewer: What kind of things would keep you from being able to go to college?

Participant: My mom and dad.

Interviewer: They don't want you to go?

Participant: Yep.

Interviewer: What would they prefer you to do?

Participant: Stay home, help them.

Interviewer: How do you feel about that?

Participant: I don't know.

No perceived barriers. Some students stated that there was nothing standing in their way or that there were no foreseeable barriers for them, as shown in the following interview:

Interviewer: Do you think there is anything that would make it hard for you to do that? Anything that would get in the way?

Participant: No.

Interviewer: Can't see anything that would get in the way or anything that would make it hard?

Participant: Yeah, can't see [anything]. 
Interviewer: There's nothing really?

Participant: Yeah.

\section{Strategies for Overcoming Identified Barriers}

Academic help from teachers and/or parents. Students expressed the belief that parents and teachers would help with school work. However, most of this support seemed geared toward helping the students finish high school rather than support their career goals:

Interviewer: Who do you go to or who could you go to for support to overcome those obstacles?

Participant: Probably like my mom, my friends.

Interviewer: How so? How would they help you? How would they be supportive?

Participant: Maybe helping out with my homework or something.

Family support, monetary and emotional. Students stated that they would go to family for support in dealing with perceived barriers. However, on further questioning, they reported that they had not talked with family members about their career goals, let alone about how they might help them overcome the barriers to reaching them. Females had greater perceived support from family, teachers, and friends than their male counterparts did:

Interviewer: OK, all right. Who do you think you can go to, or who do you think is out there to help you overcome some of those troubles of going to college?

Participant: My family, my school ...

Interviewer: Have you ever talked to either of your parents about wanting to become a doctor or teacher?

Participant: No, not yet.

Working harder in school. Students reported that they could overcome their perceived barriers by simply working harder in school:

Interviewer: Do you have some ideas about how you could get past the challenges that you have in English? What do you think would help?

Participant: Just try harder.

Financial assistance will eliminate barriers of schooling. Students expressed the belief that they could receive some type of financial aid that would eliminate the financial burden of school. Few had taken steps to research or secure scholarships. The students who had explored financial aid were typically female students who had support of their family and school staff: 
Interviewer: And what obstacle does that help you overcome?

Participant: Probably the financial one because if I get good grades then there'll be a lot of grants or money for me... scholarships.

\section{Complex Themes}

Among the complex themes were several themes that reflected a certain naïveté regarding the process of reaching career goals. There was an additional theme that reflected a perceived difficulty in going against the norms of the students' environment. The themes dealing with naïveté are explored first.

Ease of getting a job. Male students typically expressed the belief that jobs were available and that there was little training needed to secure them.

Only one barrier. Many students who identified barriers articulated one main barrier that if resolved would leave a clear path for their academic and career development.

Lack of concern or knowledge about barriers. The participants seemed unaware of and somewhat indifferent to what was required for their career goals. This also held true for those who had relatives in school or were currently working in the career in which they expressed interest. Male students identified few if any barriers, with many saying they saw nothing in the way of reaching their goals. However, they also conveyed a sense of ambivalence and uncertainty about how to achieve their goals. Female students were typically more able to discuss specific plans (e.g., naming colleges they were considering). However, similar to their male counterparts, their plans reflected little understanding of the process of achieving their career goal. This theme is reflected in one interview with a student who identified electrician, musician, and carpenter as career goals:

Interviewer: OK. Are there any things that would kind of keep you from being able to do any of those jobs?

Participant: That would keep me from away from it or ... ?

Interviewer: Yeah, keep you from being able to do it.

Participant: No.

Interviewer: So you could do any of those three without a problem you think?

Participant: Yeah.

An additional complex theme was the experience of those who discussed career options that were different from those of most participants. These indi- 
viduals appeared to struggle against the perceptions of others concerning their choice of career.

Pressure to conform to perceived social pressures. Those males who chose careers, such as artist, architect, musician, computer technician, author, or doctor, identified the perceptions of others as a significant barrier. They appeared worried and apprehensive about their ability to succeed in the face of negative pressure from their peers. Others reported feeling negative family pressure. This included being fearful of talking to parents about their careers of interest and feeling pressure to follow the career path that their parents wanted for them.

One interview went as follows:

Interviewer: Are there any things that you see kind of standing in your way from being able to do any of those kinds of jobs?

Participant: Some things ... like not being not too sure about things.

Interviewer: What kinds of things aren't you very sure about?

Participant: Like, the choices that I want to make ... I don't know if I really want to do it because, some stuff . . . that goes on, stuff around . . . like my family and stuff like that.

Interviewer: Tell me a little more.

Participant: There's just like ... it's hard to be successful or something like that.... It's just ... it feels like I'm not going to succeed as much. I'm going to be like someone else, I want to start being some ... being a worker like, you know, like everyone else, everyone in my family. Cause, people in my family, they never really, they have never really been successful. In their lives-there's lots of things....

Interviewer: So, you'd like kind of like to change that for yourself. I guess then it's kind of hard to get much support from them to do those other kinds of things you want to do.

Participant: Yeah, because sometimes you need people to talk to you about that kind of stuff. And, you know, I don't have that.

Interviewer: You don't have that in your family?

Participant: No.

Another participant expressed feeling family pressure, including fear of talking to parents or pressure to follow the career path their parents wanted them to.

This participant expressed that he wanted to be a musician and stated the following: 
Interviewer: Are [your parents] supportive?

Participant: Yeah, they are.

Interviewer: What if, like with musician, if you needed to go off to school to do that, would they be OK with that?

Participant: Yeah, a little bit. ...

Interviewer: Maybe go away, but they'd want you to come back?

Participant: Uh-huh.

Interviewer: What about the electrician? Same kind of thing?

Participant: Yeah. My mom wants me to be that.

Interviewer: Oh, your mom wants you to be an electrician?

Participant: Yeah.

Interviewer: What about your dad?

Participant: He wants me to be a doctor.

Interviewer: Oh really? What do you think about that?

Participant: I don't know . . . it looks too hard.

\section{Discussion}

This study examined Native American students' perspectives of barriers to chosen careers using a qualitative method. This method allowed the voices of the students to be heard in a way that was not defined by researchers' a priori assumptions. In other words, the method allowed for an open dialogue and provided insight that would be difficult to gain from surveys or other measures that may or may not fit students' experiences. The basic questions guiding the interviews did contain the assumption that there were barriers for Native American students in seeking a career and/or higher education. However, the method allowed even this basic assumption to be questioned.

One limitation of this study is the lack of generalizability inherent in qualitative research. All of the students in this study came from four secondary schools on the Navajo Nation. Accordingly, it is possible that the sample may not be representative of Native American students living on reservations. Another limitation may be based on the fact that the grade levels of students in this study ranged from seventh grade to seniors in high school. The potential limitation of such a variety of grade levels is that those in lower grades may not have been exposed to the same education and experiences as those in higher grades, which may have altered their perception of barriers. However, in our analysis, we did not identify any age-based differences in perceived barriers.

Several findings from this study may be of relevance for counselors and educators working with Native American students. We observed that the male 
students were considering a more limited range of possible careers than female students. In an earlier quantitative study, Lauver and Jones (1991) found that Native American boys appeared restricted in the consideration of cross-gender careers. They also found that Native Americans showed lower self-efficacy for many careers than others in the study. These findings are congruent with Gottfredson's (1981) theory, which postulates that there is a zone of acceptable alternatives that limits the career options according to sex-typical factors. Our interviews indicated particular social and family pressure against atypical career aspirations, and as a result, the students expressed internal conflict about whether to continue to work toward their goals or submit to social pressure. These students appeared to be torn between doing what they are interested in versus following the norms set by their immediate society. This was consistent with the process Gottfredson believes individuals go through in eliminating some careers options. It seemed particularly salient to the males in this study. Future research should be focused on this issue to more clearly understand this dynamic among Native Americans.

Another interesting finding was the number of students who discounted the potential effect of barriers or denied the presence of barriers altogether. Despite the fact that American Indian students in previous studies have enumerated several barriers they have encountered after high school in the transition into employment or college (A. P. Jackson \& Smith, 2001; A. P. Jackson, Smith et al., 2003), a surprising number of students in this study stated that they perceived no barriers to obtaining their career goals. Those students who did identify barriers identified only one or two barriers along with seemingly simplistic methods for overcoming these barriers. These findings occurred in spite of encouragement from interviewers to examine barriers. Interviewees were encouraged to name at least three barriers that they felt might get in their way to accomplishing their goals.

This difficulty in identifying barriers may have been caused by the isolation of reservation life and the relative lack of exposure these students have to various academic and career opportunities and accompanying barriers. The isolation of the reservation may also have limited the number of role models for specific careers contributing to the naïveté of these students concerning what it takes to complete postsecondary training or succeed in a career not visible on the reservation. Students may also have simply been in a state of denial about what it will take to accomplish these goals.

These findings point to the need to help American Indian students understand the challenges they are likely to encounter. More specific, there appears to be a continued need for education about the requirements for careers and for 
exposure to the careers and the college situations. M. A. Jackson and Nutini (2002) proposed that career interventions, particularly for those in "contexts where education and career development opportunities have been limited" (p. 57), should begin in middle school. One way to provide greater exposure to college situations and careers may be through mentoring (A. P. Jackson \& Smith, 2001). Mentoring, specifically by members of one's culture who have succeeded in higher education or careers of interest to students, may provide a way for students to recognize and understand the challenges they will likely face. This exposure might legitimize these challenges and also allow students to begin to formulate plans to overcome these obstacles. Future research should also be directed at establishing the value of mentoring for Native American students.

\section{Appendix \\ List of General Questions Asked of Participants}

1. What are careers you are interested in? (asked to name at least three careers or post-high school goals)

2. How did you become interested in this, and who do you know who does this?

3. What would stand in your way of accomplishing this?

4. Who can you go to for help to overcome this barrier?

5. What can you do now to prepare?

Another interview went as follows:

Interviewer: What are the obstacles?

Participant: Science.

Interviewer: Science. Tell me more about that.

Participant: I'm not really good at science, but I'm very good at math.

Another interview went as follows:

Interviewer: Have you ever taken any summer jobs in carpentry? Anybody around here you think you might be able to get a job with?

Participant: Yeah, my cousin's sister's boyfriend. He does those [things].

Interviewer: He does those things? Have you ever talked to him about maybe . . .

Participant: I don't know ...

Interviewer: If you talked to him, do you think he'd let you?

Participant: Yeah, probably.

Another dialogue went as follows:

Interviewer: OK. So what would be the biggest barriers in your way of getting into something like mechanic or iron worker or electrician or auto body?

Participant: I don't know. 
And another example:

Interviewer: So you want to be a mechanic. How would you go about that? How would you get into that job?

Participant: Go to school for it.

Interviewer: Where would you go?

Participant: I don't know.

\section{References}

Benjamin, D. P., Chambers, S., \& Reiterman, G. (1993). A focus on American Indian college persistence. Journal of American Indian Education, 32, 24-40.

Brown, L. L., \& Kurpius, S. E. R. (1997). Psychosocial factors influencing academic persistence of American Indian college students. Journal of College Student Development, 38, 3-12.

Gottfredson, L. S. (1981). Circumscription and compromise: A developmental theory of occupational aspirations. Journal of Counseling Psychology, 28(6), 545-577.

Hoover, J. J., \& Jacobs, C. C. (1992). A survey of American Indian college students: Perceptions toward their study skills/college life. Journal of American Indian Education, 32, 21-29.

Hoshmand, L. T. (1989). Alternate research paradigms: A review and teaching proposal. The Counseling Psychologist, 17, 3-79.

Jackson, A. P., \& Patton, M. J. (1992). A hermeneutic approach to the study of values in counseling, Counseling and Values, 36, 201-209.

Jackson, A. P., Slife, B. D., \& Williams, D. C. (2003). Relationism: A non-lethal philosophy for counseling psychology. Manuscript submitted for publication.

Jackson, A. P., \& Smith, S. A. (2001). Postsecondary transitions among Navajo Indians. Journal of American Indian Education, 40(2), 28-47.

Jackson, A. P., Smith, S. A., \& Hill, C. L. (2003). Academic persistence among Native American college students. Journal of College Student Development, 44(4), 548-565.

Jackson, A. P., \& Turner, S. (2004). Counseling and psychotherapy with Native Americans. In T. Smith (Ed.), Practicing multiculturalism (pp. 215-233). Boston: Allyn \& Bacon.

Jackson, M. A., \& Nutini, C. D. (2002). Hidden resources and barriers in career learning assessment with adolescents vulnerable to discrimination. Career Development Quarterly, 51(1), 56-77.

Kvale, S. (1987). Validity in the qualitative research interview. Methods, 1, 37-72.

Kvale, S. (1996). Interviewing: An introduction to qualitative research interviewing. Thousand Oaks, CA: Sage.

Lauver, P. J., \& Jones, R. M. (1991). Factors associated with perceived career options in American Indian, White, and Hispanic rural high school students. Journal of Counseling Psychology, 38(2), 159-166.

Lin, R., LaCounte, D., \& Eder, J. (1988). A study of Native American students in a predominantly White college. Journal of American Indian Education, 27, 8-15.

Luzzo, D. A. (1993). Ethnic differences in college students' perceptions of barriers to career development. Journal of Multicultural Counseling \& Development, 21(4), 227-236. 
Luzzo, D. A., \& McWhirther, E. H. (2001). Sex and ethnic differences in the perception of educational and career-related barriers and levels of coping efficacy. Journal of Counseling and Development, 79(1), 61-67.

McWhirther, E. H. (1997). Perceived barriers to education and career: Ethnic and gender differences. Journal of Vocational Behavior, 50, 124-140.

Packer, M. J. (1985). Hermeneutic inquiry in the study of human conduct. American Psychologist, 40, 1081-1093.

Polkinghorne, D. E. (1984). Further extensions of methodological diversity for counseling psychology. Journal of Counseling Psychology, 31, 416-429.

Polkinghorne, D. E. (1991, April). Generalization and qualitative research: Issues of external validity. Paper presented at the American Educational Research Association Annual Meeting, Chicago.

Reddy, M. A. (Ed.). (1993). Statistical record of native North Americans. Washington, DC: Gale Research.

Schwandt, T. A. (2000). Three epistemological stances for qualitative inquiry. In N. K. Denzin \& Y. S. Lincoln (Eds.), Handbook of qualitative research (2nd ed., pp. 189-213). Thousand Oaks, CA: Sage.

Swanson, J. L., \& Tokar, D. M. (1991). College students' perceptions of barriers to career development. Journal of Vocational Behavior, 38, 92-106.

U.S. Bureau of the Census. (1990). Characteristics of American Indians by tribe and selected areas. Washington, DC: U.S. Government Printing Office.

U.S. Department of Commerce. (1993). We the first Americans. Washington, DC: U.S. Government Printing Office.

U.S. Department of Education. (1998). American Indians and Alaska natives in postsecondary education. Washington, DC: U.S. Government Printing Office.

Laura L. Hoffman is completing her Ph.D. in counseling psychology at Brigham Young University. Her dissertation research was a qualitative study of deteriorating clients in group counseling.

Aaron P. Jackson is an associate professor of counseling psychology at Brigham Young University. He conducts research on Native American students' academic and career development. He also has interests in the philosophies and values that undergird counseling theories and interventions.

Steven A. Smith is an associate clinical professor at Brigham Young University's Counseling and Career Center. His research focuses on the academic self-efficacy of Native American students. 